\title{
Students Who Surprise Teachers When Learning Mathematics Through Problem Solving in the Early Primary Years
}

\author{
James Russo $^{\mathrm{a}}$, Janette Bobis ${ }^{\mathrm{b}}$, Ann Downton ${ }^{\mathrm{a}}$, Sally Hughes ${ }^{\mathrm{a}}$, Sharyn Livy ${ }^{\mathrm{a}}$, Melody McCormick ${ }^{\mathrm{a}}$, \\ and Peter Sullivan ${ }^{\mathrm{a}}$
}

Corresponding author: James Russo (james.russo@monash.edu)

${ }^{a}$ Faculty of Education, Monash University, Clayton VIC 3168, Australia

${ }^{b}$ The University of Sydney, Sydney NSW 2006, Australia

Keywords: epistemic emotions, teacher surprise, teacher perceptions, primary education, mathematics education, problem-solving

\begin{abstract}
Teacher reluctance to teach mathematics through challenging tasks is frequently linked to beliefs that such approaches are not appropriate for students perceived as less mathematically capable. One potential means of shifting such beliefs is inviting teachers to reflect on students that surprise them when working on such tasks. Early years' primary teachers $(n=160)$ participated in a professional learning initiative that supported them to implement up to ten sequences of challenging tasks in their classrooms across the school year. When asked to describe a student who surprised them when working on the sequences, approximately half (47\%) of teachers described students previously assumed to be less mathematically capable being successful in their mathematical learning. Most remaining teachers (36\%) commented on the depth of student mathematical thinking and positive learning dispositions demonstrated, without making any explicit reference to preconceptions of student capability. By contrast, a notable number of teachers $(15 \%)$ instead described their surprise at how students labelled as mathematically capable struggled with working on tasks that were more open-ended, had multiple solutions, and required them to explain their reasoning. Our findings suggest that teaching with sequences of challenging tasks has the potential to disrupt rigid teacher preconceptions as to whom might be considered a mathematically capable student.
\end{abstract}

\section{Introduction}

Recently, teachers in many countries, including Australia, have been encouraged to utilise more challenging tasks in mathematics instruction and be willing to teach mathematics through problem solving (Cheeseman, Clarke, Roche, \& Wilson, 2013; Russo, 2019; Stein, Engle, Smith, \& Hughes, 2008). Challenging tasks have been described as thought-provoking and absorbing mathematical problems that strive to include all students in a lesson, through possessing characteristics such as being simply posed, having rich mathematical potential, and allowing students to access enabling and extending prompts developed prior to the delivery of the lesson (Sullivan \& Mornane, 2014). In parallel to including more challenging tasks in instruction, it is often suggested that teachers structure their lessons to facilitate problem-based approaches to learning mathematics (Lampert, 2001). This involves launching the task with minimal explanation, with the focus being on setting expectations and orientating students to the tools they have at their disposal for working on the task. Students then explore the task individually and/or in small groups, whilst the teacher roams around, asking provocative questions and supporting students to reason mathematically. The final phase of the lesson is a whole-class teacher-facilitated mathematical discussion, where selected students present their work in a thoughtfully sequenced manner, and the teacher supports students to make connections back to the underlying mathematical ideas (Sherin, 2002; Stein et al., 2008).

Despite the apparent efficacy of such approaches (Sullivan et al., 2020), teachers are at times reluctant to pose challenging tasks to students and to teach mathematics through problem-solving (Darragh, 2013). One reason for this reluctance may be the level of pedagogical skill and knowledge required to facilitate effective learning through using such tasks (Charalambous, 2008; Giacomone, Beltrán-Pellicer, \& Godino, 2019). 
However, this reluctance has also been linked to teacher beliefs and preconceptions about for whom such tasks are appropriate. In particular, some teachers voice concerns that such challenging content may not be suitable for students perceived as 'low-performing'; although there is evidence from small-scale qualitative studies that such students can surprise teachers with their ability to cope with such tasks (e.g., Ingram et al., 2020). The current study represents a systematic, larger-scale attempt to explore the students that surprise teachers when working on sequences of challenging tasks in early primary mathematics classrooms, and what specifically teachers find surprising about these students' responses.

\section{Literature Review}

\section{Surprise in a learning context}

Surprise is an emotion, a key characteristic of which is to focus an individual's attention on the surpriseeliciting event (Schützwohl, 1998). This focussing of attention arises from a schema-discrepancy, understood as the psychological distance between an individual's expectations and what is actually observed. Combined with the intensity of the emotional experience of surprise, it is this schema-discrepancy responsible for the tendency for surprising events to be both memorable and contemplated (Schützwohl, 1998).

Surprise, and other related epistemic emotions, such as awe and wonder, have been put forward as potentially powerful mechanisms for motivating and generating learning in children (Stahl \& Feigenson, 2017; Valdesolo, Schtulman, \& Baron, 2017). Adults have less frequently been the focus of explorations into the relationship between epistemic emotions and learning, and when they have been, this research has generally been undertaken in laboratory, rather than applied, settings (e.g., Foster \& Keane, 2015; Reisenzein \& Studtmann, 2007). One purpose of the current study is to examine surprise in a teacher professional learning context. Specifically, Australian early years' primary teachers were supported to implement sequences of learning involving challenging mathematical tasks with their students using a problem-based lesson structure, and then asked to describe a student who surprised them during work on the sequences.

The notion that teacher surprise might be a mechanism that at least partially underpins changes in teacher beliefs about learning has been explored in other professional learning contexts, in particular, through the work of Timperley and colleagues (Timperley \& Robinson, 2001; Timperley \& Phillips, 2003; Timperley, 2005). For instance, Timperley (2005) found that encouraging teachers to track data in relation to student performance generated surprise about the level of growth achieved by particular students, which in turn helped to enthuse teachers about pursuing data-driven approaches to support more targeted instruction. Timperley suggested that surprise can be a valuable tool in a professional learning context, particularly to shift deeply embedded teacher beliefs and practices.

However, before considering how surprise can be deliberately harnessed as a professional learning tool, further research is needed to establish two pre-conditions. The first is that surprise is in fact a salient construct from the perspective of teachers when reflecting on classroom learning experiences. This can be gleaned from whether teachers can meaningfully respond to an item asking them to report on an incident, or series of incidents, in the classroom where they experienced surprise. The second is that designers of professional learning are able to at least partially anticipate what teachers will find surprising when implementing teaching and learning experiences suggested in the professional learning. Without such foreknowledge, teacher surprise becomes an unpredictable force in shaping teacher beliefs and practices. If this is the case, professional learning designers may be tempted to mitigate surprise, rather than embrace it as a potentially powerful force to be utilised. In this paper, we test this idea by drawing on the literature in an attempt to anticipate the types of students that might surprise teachers when they implement sequences of challenging tasks in the classroom, and then comparing it to what study teachers reported. 


\section{What might surprise teachers when teaching with sequences of challenging tasks?}

One seemingly common belief that some teachers hold prior to teaching with challenging tasks is that such tasks should only be for "high flyers", and that it is the teacher's responsibility to protect students identified as "low-performing" from difficult mathematics. In the words of one particular teacher involved in an earlier iteration of the current project: "They were in that low group... I suppose I never wanted to pose the challenge because I didn't want them to think that maths was hard.” (Russo et al., 2019, p. 13).

Indeed, there is evidence that a reluctance to allow low-performing students to struggle with challenging tasks prevails beyond early years teachers and the Australian educational context. For example, Ingram et al. (2020) administered a questionnaire to $12 \mathrm{New}$ Zealand upper primary teachers before their participation in professional learning around teaching with challenging tasks. There was a general belief amongst these teachers that challenging tasks were more appropriate for high-performing students, and alternative tasks would need to be prepared for students "identified as not being able to meet the challenges required of openended problem-solving" (p. 11). Likewise, Leikin, Levav-Waynberg, Gurevich, and Mednikov (2006) found that most of the 30 Israeli upper secondary teachers participating in a professional learning program focused on encouraging problem-based approaches to teaching mathematics remained reluctant to adopt this pedagogical model. A major concern described by study teachers was that such approaches were not appropriate for students who have difficulties in mathematics.

However, such views of teachers are frequently revised after being provided with substantial opportunities to implement challenging tasks in their own classrooms. The Ingram et al. (2020) study is particularly informative here. When reporting back on their experiences teaching mathematics through problem solving, many teachers commented on the "swap of positioning" within the classroom (p. 514). In particular, some students previously labelled as high-performing struggled, whilst low-performing students often excelled, at least relative to their typical experience in a regular mathematics lesson.

Other studies have shown some teachers remain more equivocal about the capacity of low-performing students to cope with learning mathematics through more challenging tasks, even after being immersed in classrooms adopting such pedagogies (Silver, Ghousseini, Gosen, Charalambous, \& Strawhun, 2005). However, there is evidence that even some of these more ambivalent teachers report surprise at the progress such students make when working on units of work built around challenging tasks. For example, Russo and Hopkins (2019) describe one such ambivalent teacher's reaction to observing a particular student with an intellectual disability engage with challenging tasks, even when she did not have one-to-one support: "She was able to use some strategies - it was quite amazing really - draw on some number facts that she knew to try and work things out." (p. 770).

\section{How might surprising events impact on teacher beliefs?}

Given the above literature, and, in particular, the Ingram et al. (2020) study, we would expect most students who surprise teachers when working on challenging tasks to fall into one of two categories. First, students previously identified as "low-performing" might demonstrate surprising mathematical capabilities or mathematical dispositions when working on such tasks. Second, students previously identified as "highperforming" might struggle unexpectedly, either with the mathematics content or in demonstrating the types of dispositions (e.g. persistence) frequently identified as important during work on such tasks.

We have adapted Valdesolo et al.'s (2017) model of epistemological emotions and combined it with the above literature to formulate a preliminary model about how teacher surprise around how particular students cope with challenging tasks can lead to changes in teacher beliefs about who challenging tasks are suitable for (see Figure 1). The model includes an illustrative internal monologue mapping anticipated changes in teacher beliefs as teachers' experience, and then seek to make sense of, students who surprise them when working on the sequences. The current study is limited to examining Step 2 in the model. 

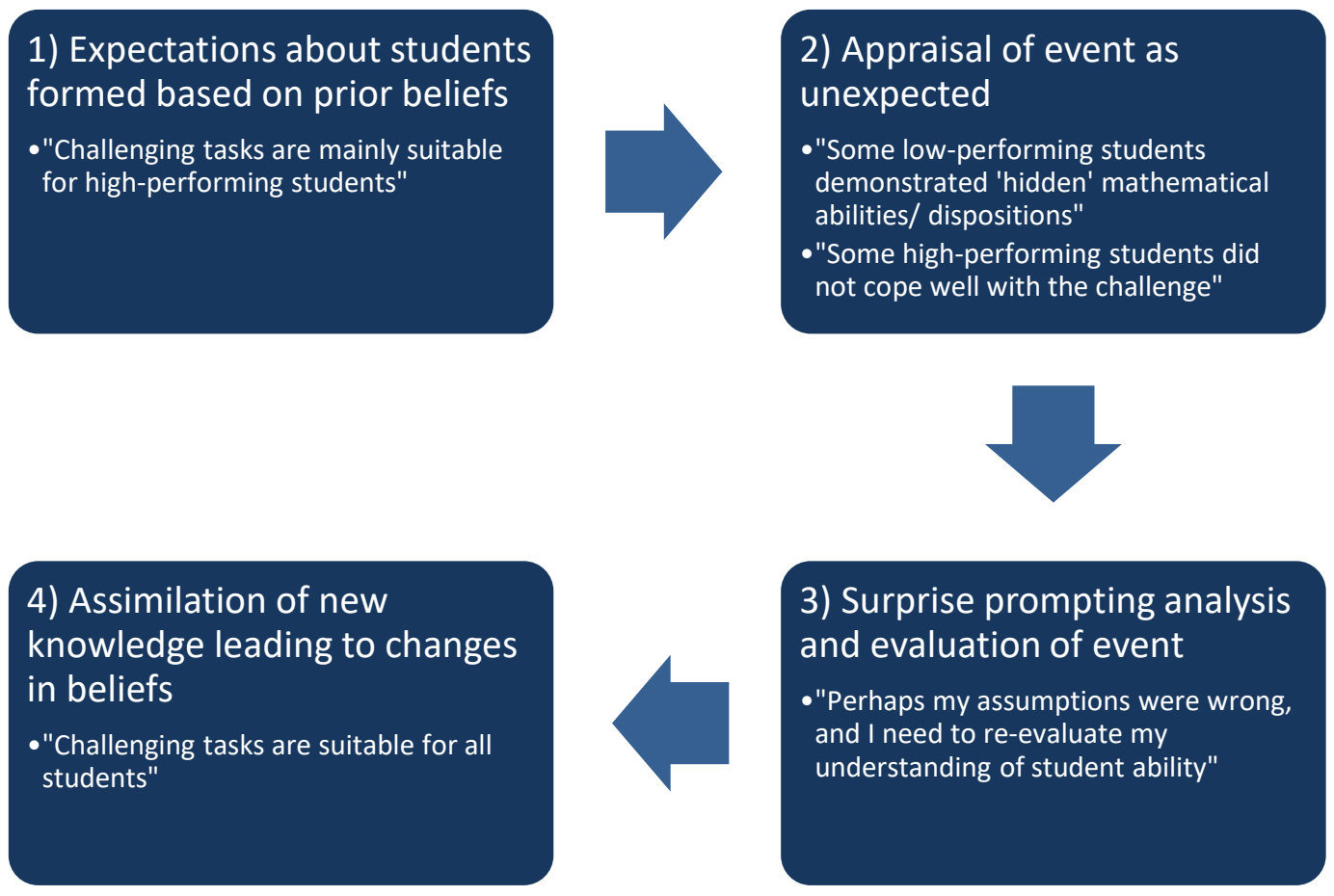

Figure 1. Model describing how teacher surprise can shape teacher beliefs about student performance when teaching mathematics through problem-solving.

\section{Method}

Participants were 160 primary school teachers and teacher-leaders currently working with Foundation, Year 1, and Year 2 students (5-8 year olds) who participated in a program of professional learning focused on teaching mathematics through sequences of challenging tasks. Participants came from a diverse range of government schools (14 schools) and Catholic schools (24 schools) across two Australian states.

Participants were provided with one full day of professional learning overviewing how to teach mathematics through challenging tasks, access to a resource booklet outlining ten learning sequences built around challenging tasks (each equating to approximately one to two weeks of mathematics learning), and some inschool support to plan these learning sequences. For more information about the principles underpinning the professional learning and related pedagogies, see Sullivan et al. (2020).

During a follow-up professional learning day towards the end of the school year, participants were given an opportunity to complete an online questionnaire (using the program Qualtrics) reporting their experiences of teaching the sequences. The questionnaire item relevant to the current paper was: Think of a student that surprised you when working on the learning sequences. Describe what happened and what surprised you.

\section{Analytical Approach}

Our efforts to thematically analyse the data approximated the process outlined by Braun and Clarke (2006). After familiarising ourselves with the data, initial codes were generated. Specifically, each participant response was coded as either referring to low-performing students, high-performing students, or coded as making no reference to student performance. In addition, each response was also coded according to whether the comment described teacher surprise involving students experiencing success with the sequence, or teacher surprise involving students struggling with the sequence. This created a three by two classification scheme (see Table 1, Column 1).

After coding participants' responses along the two aforementioned dimensions, each response was read and re-read to ascertain what specifically had surprised teachers about their chosen student; that is, why did they 
perceive their chosen student to have had surprising success with the sequence (or to have surprisingly struggled with the sequence). This process involved first identifying key words (including synonyms of these key words) used by a teacher to describe the student, or actions taken by the student, during their work on the sequences, and coding responses accordingly. The final list of key words identified included: understanding, explaining, persistence, independence, engaged, and confidence.

All participant responses were then re-read more holistically, and coded to additional key words where relevant. For example, one participant responded, "My lowest student was able to identify the correct way to work out the length of the line using the string. She shared her thinking and strategies with the class. A definite 'wow' moment." This response had been initially coded to the key word "explaining" based on the teacher's use of the phrase "shared her thinking". However, reading the response more holistically resulted in it also being coded to "understanding", because the response clearly conveys that this particular student had surprised the teacher with her mathematical understanding of the length concept.

This holistic coding process also allowed descriptions of high-performing students who struggled to be coded according to the same key word classification scheme, instead focussing on the difficulties experienced by these students. For example, the following response was coded to explaining and confidence: "A student who is really high in number work really struggled with the tasks, with recording the methods to work through the learning sequences. He was really out of his comfort zone and never knew if he was 'right'". Finally, these six key words were then aggregated into two themes, delineated according to whether they referred to mathematical thinking (understanding, explaining) or student dispositions towards their mathematical learning (persistence, independence, engaged and confidence).

\section{Results and Discussion}

Before considering the substance of teacher responses, it is worth noting that all teachers who completed the questionnaire managed to describe a student who surprised them when working on the sequences. This implies that the notion of surprise was indeed salient to teachers in this context.

Turning our attention to Table 1, we can make several observations about the characteristics of students that surprised teachers. First, more than five times as many teachers $(84 \%)$ described a student who was surprisingly successful when working on the sequences of challenging tasks, compared with a student who surprisingly struggled (16\%). This is consistent with prior research suggesting that young students in general can cope with more complex and cognitively demanding tasks than most primary teachers initially anticipate (Russo et al., 2019; Sullivan et al., 2015), and alludes to the benefits of exposing younger students to more sophisticated mathematics (Albarracína \& Gorgorióa, 2019). Second, most teachers conveyed being surprised by student mathematical thinking (85\%), in particular students' level of understanding, and their capacity to explain, record and communicate their thinking to others. However, a substantial minority of teachers (39\%) were surprised by students' learning dispositions, such as their level of persistence, capacity to work independently and confidently, and their engagement in the mathematics. These observations are consistent with literature suggesting that innovative teaching approaches frequently simultaneously improve student conceptual knowledge and attitudes towards mathematics (e.g., Chen, Van Dooren, \& Verschaffel, 2015; Higgins, 1997; Simamora \& Saragih, 2019; Tok, Bahtiyar, \& Karalök, 2015). Third, when teachers mentioned student performance in their response, they tended to either describe low-performing students having surprising success with the sequence, or high-performing students surprisingly struggling with the sequence. This is to be expected, given that a low-performing student struggling, or a high-performing student having success, is less likely to be surprising. That teaching with challenging tasks generated such reactions from teachers had been suggested from previous studies (Ingram et al., 2020), and was included in our model outlined in Figure 1. However, it is worth noting that teachers were approximately three times more likely to describe a low-performing student having success with the sequence (47\%) than a highperforming student struggling (15\%), again consistent with prior research suggesting that teachers 
underestimate student mathematical capacity when engaging with more challenging tasks (Sullivan et al., 2015). Finally, it is clear from Table 1 that when student performance was not explicitly mentioned, in almost every instance, teachers also referred to being surprised by the level of success students experienced when working on the sequences. To illuminate these findings, explanations of how low-performing students, high-performing students, and students for whom performance was not explicitly mentioned surprised teachers, are elaborated on below with illustrative quotes included.

Table 1. Students that surprised teachers during the learning sequences ( $n=160$ teachers)

\begin{tabular}{cllll}
\hline & $\begin{array}{l}\text { Mathematical } \\
\text { Thinking only }\end{array}$ & $\begin{array}{l}\text { Learning } \\
\text { Dispositions only }\end{array}$ & $\begin{array}{l}\text { Both thinking and } \\
\text { dispositions }\end{array}$ & Total \\
\hline $\begin{array}{c}\text { Low-performing Students } \\
\text { Having success* } \\
\text { Struggling }\end{array}$ & $36(23 \%)$ & $13(8 \%)$ & $25(16 \%)$ & $75(47 \%)$ \\
$\begin{array}{l}\text { High-performing Students } \\
\text { Having success }\end{array}$ & $0(0 \%)$ & $0(0 \%)$ & $0(0 \%)$ & $0(0 \%)$ \\
$\quad \begin{array}{l}\text { Struggling } \\
\text { No reference to perceived student } \\
\text { performance }\end{array}$ & $1(1 \%)$ & $1(1 \%)$ & $0(0 \%)$ & $2(1 \%)$ \\
$\quad \begin{array}{l}\text { Having success } \\
\text { Struggling }\end{array}$ & $16(10 \%)$ & $0(0 \%)$ & $8(4 \%)$ & $24(15 \%)$ \\
Total & $1(1 \%)$ & $0(0 \%)$ & $7(4 \%)$ & $1(1 \%)$ \\
& $96(60 \%)$ & $23(14 \%)$ & $40(25 \%)$ & 160 \\
\hline
\end{tabular}

*Note: One teacher did not specify how a low-performing student surprised her.

\section{Low-performing students having success}

Approximately half of the teachers indicated their surprise at a student perceived as low-performing having success when working on the sequences. Generally, teachers were surprised by these students' levels of mathematical understanding, the insightful strategies they employed, and their capacity to explain their thinking to other students. Interestingly, when teachers commented on the specific mathematical content focus during which the surprising incident occurred, they frequently mentioned one of the measurement sequences:

One of my low students who struggles with oral language did a brilliant job on the time sequence and was able to explain and justify his thinking... (Teacher 27).

Ben who was not a confident maths student used a table to organise his thinking. It was so simple, yet accurate. When he shared with the class it was amazing... great feedback from his peers. (Teacher 3).

One teacher described how the ability of students previously perceived as low-performing to cope with the sequences of challenging tasks led them to re-evaluate their assumption of what particular students were capable of:

When first implementing the sequence I would launch students into a task and assume that my 'vulnerable' students wouldn't be able to access the learning. I quickly learnt not to make those assumptions. I was taken aback at the level of work they were producing. (Teacher 36).

Other teachers emphasised the cultivation of desirable learning dispositions by students perceived as lowperforming, in particular, their independence when working on tasks, their confidence and their willingness to persist with challenge: 
I have a student who needs constant one on one support. It was really rewarding to see this student independently have success during the Volume Unit. (Teacher 63).

One of the biggest surprises was from a student who wasn't confident with their understanding of numbers and how they worked. They struggled with the task and initially found it difficult to work independently on the task (it was one of the first sequences we completed). When they persevered and stuck to it, after some reflections and enabling prompts, the student was able to find a solution to the problem (L shapes piece). The student sticking with it and working to complete the task independently surprised me. (Teacher 100).

Importantly, many teachers commented on the development of these learning dispositions in parallel to the development of the child's mathematical thinking:

Lilly lacked confidence in Maths and had gaps in her knowledge... Her persistence and interest in listening to other strategies and (to) have a go surprised me. She ended up having some of the most efficient strategies... and was able to explain her thinking proudly. (Teacher 108).

One of my students at the beginning of doing the sequences would not complete or attempt any task independently without teacher support. He always would come up to me and say that it was too hard. As we progressed through the sequences he became more independent and gained confidence in his ability to complete tasks. By the end he was able to write, draw and attempt to write a statement about his thinking. The child is now able to explain his thinking to the class and use a variety of strategies to solve problems. (Teacher 24).

\section{High-performing students struggling}

Some teachers indicated their surprise at a student previously perceived as high-performing struggling when working on the sequences of challenging tasks, particularly initially. Teachers often commented that these students found the openness of the tasks to be a barrier, as well as the expectation that they explain the thinking behind their response:

One of my higher students struggled with the openness of the task and when asked to prove answers, struggled to think of reasons why. (Teacher 134).

One of my typical high flyers really struggled with communicating and reasoning his answers when working with operations. (Teacher 154).

However, several teachers noted that, over time, these high-performing students who had initially struggled with the sequences were able to make progress, particularly in terms of the learning dispositions needed for success with challenging tasks. For example:

Isabel is a highly able student who performs well above the curriculum; however, when presented with open-ended questions found it challenging to understand what was expected of her. Over time and some serious confidence building, she was able to build on her strategies of having a go and not being concerned about what 'finished' looked like. (Teacher 18).

Interestingly, the point was made that low-performing students could serve as role-models for highperforming students in terms of demonstrating these learning dispositions:

High achievers initially found this sequence very difficult because of their past experiences of maths being easy... the challenge of new learning was something they had not yet experienced. Many of these students were supported by students that were used to the struggle. (Teacher 54).

\section{No reference to perceived student performance}

Over-one third of teachers (37\%) commented on a student who surprised them without making any explicit reference to the perceived prior mathematical performance level of the student. However, as highlighted earlier, it is noteworthy that all but one of these teachers (58 out of 59 teachers) indicated their surprise at the success a student had whilst working on the sequences of challenging tasks, rather than being surprised at a student struggling. Most of the comments related to surprise at the sophistication of student 
mathematical thinking, including their ability to reason mathematically, explain their thinking, identify patterns, and find multiple solutions to challenging tasks:

One particular student was able to come up with multiple answers and was able to explain his thinking and reasoning for his answers. (Teacher 2).

One particular student who I wasn't aware had such strengths in number really did well in showing his thinking in multiple ways and discovering multiple solutions. He also developed throughout the year in his ability to explain his thinking. (Teacher 77).

On occasion, teachers also made links between the quality of these students' mathematical thinking, and the cultivation of a productive learning disposition, including qualities such as confidence, resilience, and persistence:

I was surprised when the student realised ten more and ten less, recognising the patterns on the number chart. He could link this to other numbers. It was a light bulb moment for him and then he was more confident to try more tasks and his attitude changed to a more positive outlook at trying other tasks he wasn't familiar with. (Teacher 159).

The particular student used the learning from the warm ups to assist in the rich tasks. She was completely engaged and proud of her success. She often found more solutions and accepted challenges willingly. The tasks were open enough for her to achieve as high or wide as her thinking took her. (Teacher 97).

\section{Conclusions and Implications}

The current study endeavoured to establish that getting teachers to think about students who surprise them when working on sequences of challenging mathematical tasks is a salient exercise. Based on prior literature (e.g., Leikin et al., 2006), we had reason to suspect that many participating teachers might initially hold the view that students they had identified as low-performing should not engage with challenging mathematical work, and therefore would be surprised when some students characterised in this manner had success with the sequences. This is indeed what we found. Similarly, another albeit smaller group of teachers described a student assumed to be high-performing not always responding to more challenging work as anticipated, at least initially.

Together, these findings suggest that teaching with challenging tasks has the potential to disrupt established classroom dynamics around who is considered the low-performing and high-performing students in the mathematics classroom, a phenomenon also noted by Ingram et al. (2020). Such surprising experiences may encourage teachers to be more circumspect about the potential utility of grouping students according to prior mathematical performance; a practice that is frequently criticised for being academically inequitable (Cheeseman \& Klooger, 2018), damaging to some students' identities as learners (McGillicuddy \& Devine, 2020), and overly dismissive of the benefits of exposing students to mathematical ideas currently beyond their grasp (Faragher \& Clarke, 2019). As outlined in Figure 1, it might also help to shift teachers away from the related belief that "Challenging tasks are mainly suitable for high-performing students"; a belief that is contradicted by studies that show consistent negative correlations between prior student performance and learning gains achieved during units of work built around challenging tasks, including in the early primary years (Gilbert et al., 2014; Russo, 2017). Such negative correlations in fact suggest that it is actually lowerperforming students who learn most when engaging with challenging tasks; and teachers who think otherwise might be confusing performance (e.g., the ability to 'finish' a task) with learning (Russo \& Hopkins, 2019).

It is important to note that it is not necessary for teachers to perceive all, or even most, "low-performing" students as having surprising success in order to challenge the preconception that challenging tasks are predominantly for "high fliers" (Russo et al., 2019, p. 13). The power of surprise in a professional learning context is that it results in participants attributing disproportionate significance to unexpected events. Through encouraging reflection on those students' that surprised, we believe that teachers can open themselves up to the idea that sequences of challenging tasks are suitable for all students learning 
mathematics, with such tasks differentiated through the use of enabling and extending prompts (Sullivan et al., 2006).

Future research could endeavour to harness the idea of surprise more explicitly. For example, participants might be encouraged to keep a lesson diary documenting occasions where they are surprised by a student when working on sequences of challenging tasks. The beliefs of this group of teachers concerning whom challenging tasks are suitable for could be subsequently contrasted with another group of teachers that did not maintain such a diary, to examine whether becoming more cognisant of 'students who surprise' actually shifts teacher beliefs.

\section{Acknowledgments}

The research that formed the basis of this article was funded by the Australian Research Council, Catholic Education Diocese of Parramatta, and Catholic Education Melbourne (LP 180100611). The views expressed are the opinions of the authors who take full responsibility for the ethical conduct of the research and preparation of the report.

\section{References}

Albarracín, L., \& Gorgorió, N. (2019). Using large number estimation problems in primary education classrooms to introduce mathematical modelling. International Journal of Innovation in Science and Mathematics Education, 27(2), 45-57.

Braun, V., \& Clarke, V. (2006). Using thematic analysis in psychology. Qualitative Research in Psychology, 3(2), 77101. https://doi.org/10.1191/1478088706qp063oa

Charalambous, C. Y. (2008). Mathematical knowledge for teaching and the unfolding of tasks in mathematics lessons: Integrating two lines of research. In O. Figueras, J. Cortina, S. Alatorre, T. Rojano \& A. Sepúlveda (Eds.), Proceedings of the 32nd conference of the International Group for the Psychology of Mathematics Education (pp. 281-288). Morelia, Mexico: PME.

Cheeseman, J., Clarke, D.M., Roche, A., \& Wilson, K. (2013). Teachers' views of the challenging elements of a task. In V. Steinle, L. Ball \& C. Bardini (Eds.), Proceedings of the 36th annual conference of the Mathematics Education Research Group of Australasia (pp. 154-161). Melbourne, Australia: MERGA.

Cheeseman, J., \& Klooger, M. (2018). Mathematics teachers: Dealing with difference. Australian Primary Mathematics Classroom, 23(3), 27-29.

Chen, L., Van Dooren, W. \& Verschaffel, L. (2015). Enhancing the development of Chinese fifth-graders' problemposing and problem solving abilities, beliefs, and attitudes: a design experiment. In F. M. Singer, N. F. Ellerton \& J. Cai (Eds.), Mathematical problem posing: from research to effective practice (pp. 309-329). New York: Springer. https://doi.org/10.1007/978-1-4614-6258-3_15

Darragh, L. (2013). Sticking with it or doing it quickly: What performances do we encourage in our mathematics learners? In V. Steinle, L. Ball \& C. Bardini (Eds.), Proceedings of the 36th annual conference of the Mathematics Education Research Group of Australasia (pp. 218-225). Melbourne, Australia: MERGA.

Faragher, R. M., \& Clarke, B. A. (2019). Inclusive practices in the teaching of mathematics: some findings from research including children with Down syndrome. Mathematics Education Research Journal. https://doi.org/10.1007/s13394-019-00294-x

Foster, M. I., \& Keane, M. T. (2015). Why some surprises are more surprising than others: Surprise as a metacognitive sense of explanatory difficulty. Cognitive Psychology, 81, 74-116. https://doi.org/10.1016/j.cogpsych.2015.08.004

Giacomone, B., Beltrán-Pellicer, P., \& Godino, J. D. (2019). Cognitive analysis on prospective mathematics teachers' reasoning using area and tree diagrams. International Journal of Innovation in Science and Mathematics Education, 27(2), 18-32.

Gilbert, M. C., Musu-gillette, L. E., Woolley, M. E., Karabenick, S. A., Strutchens, M. E., \& Martin, W. G. (2014). Student perceptions of the classroom environment: Relations to motivation and achievement in mathematics. Learning Environments Research, 17(2), 287-304. https://doi.org/10.1007/s10984-013-9151-9

Higgins, K. M. (1997). The effect of year-long instruction in mathematical problem solving on middle-school students' attitudes, beliefs, and abilities. The Journal of Experimental Education, 66(1), 5-28. https://doi.org/10.1080/00220979709601392

Ingram, N., Holmes, M., Linsell, C., Livy, S, McCormick, M., \& Sullivan, P. (2020). Exploring an innovative approach to teaching mathematics through the use of challenging tasks: a New Zealand perspective. Mathematics Education Research Journal, 32(3), 497-522. https://doi.org/10.1007/s13394-019-00266-1

Lampert, M. (2001). Teaching problems and the problems of teaching. New Haven: Yale University Press.

Leikin, R., Levav-Waynberg, A., Gurevich, I., \& Mednikov, L. (2006). Implementation of multiple solution connecting tasks: Do students' attitudes support teachers' reluctance? Focus on Learning Problems in Mathematics, 28(1), 1-22. 
McGillicuddy, D., \& Devine, D. (2020). 'You feel ashamed that you are not in the higher group' —Children's psychosocial response to ability grouping in primary school. British Educational Research Journal. https://doi.org/10.1002/berj.3595

Reisenzein, R., Studtmann, M. (2007). On the expression and experience of surprise: No evidence for facial feedback, but evidence for a reverse self-inference effect. Emotion, 7(3), 612-627. https://doi.org/10.1037/1528-3542.7.3.612

Russo, J. A. (2017). Examining the impact of lesson structure when teaching with cognitively demanding mathematical tasks in the early primary years (Unpublished doctoral dissertation).

https://bridges.monash.edu/articles/thesis/Examining_the_impact_of_lesson_structure_when_teaching_with_cogniti vely_demanding_mathematical_tasks_in_the_early_primary_years/5106877/1

Russo, J. (2019). Walking the line between order and chaos: A teacher-researcher's reflection on teaching mathematics with challenging tasks in primary classrooms. International Journal of Innovation in Science and Mathematics Education, 27(3), 14-24.

Russo, J., Bobis, J., Downton, A., Hughes, S., Livy, S., McCormick, M., \& Sullivan, P. (2019). Teaching with challenging tasks in the first years of school: What are the obstacles and how can teachers overcome them? Australian Primary Mathematics Classroom, 24(1), 11-18.

Russo, J., \& Hopkins, S. (2019). Teachers' perceptions of students when observing lessons involving challenging tasks. International Journal of Science and Mathematics Education, 17(4), 759-779 https://doi.org/10.1007/s10763-0189888-9

Schutzwohl, A. (1998). Surprise and schema strength. Journal of Experimental Psychology: Learning, Memory and Cognition, 24(5), 1182-1199. https://doi.org/10.1037/0278-7393.24.5.1182

Sherin, M. G. (2002). When teaching becomes learning. Cognition and Instruction, 20(2), 119-150. https://doi.org/10.1207/s1532690xci2002_1

Silver, E. A., Ghousseini, H., Gosen, D., Charalambous, C., \& Strawhun, B. T. F. (2005). Moving from rhetoric to praxis: Issues faced by teachers in having students consider multiple solutions for problems in the mathematics classroom. The Journal of Mathematical Behavior, 24(3-4), 287-301. https://doi.org/10.1016/j.jmathb.2005.09.009

Simamora, R. E., \& Saragih, S. (2019). Improving students' mathematical problem solving ability and self-efficacy through guided discovery learning in local culture context. International Electronic Journal of Mathematics Education, 14(1), 61-72. https://doi.org/10.12973/iejme/3966

Stahl, A. E., \& Feigenson, L. (2017). Expectancy violations promote learning in young children. Cognition, 163, 1-14. https://doi.org/10.1016/j.cognition.2017.02.008

Stein, M. K., Engle, R. A., Smith, M. S., \& Hughes, E. K. (2008). Orchestrating productive mathematical discussions: Five practices for helping teachers move beyond show and tell. Mathematical Thinking and Learning, 10(4), 313340. https://doi.org/10.1080/10986060802229675

Sullivan, P., Askew, M., Cheeseman, J., Clarke, D., Mornane, A., Roche, A., \& Walker, N. (2015). Supporting teachers in structuring mathematics lessons involving challenging tasks. Journal of Mathematics Teacher Education, 18(2), 123-140. https://doi.org/10.1007/s10857-014-9279-2

Sullivan, P., Bobis, J., Downton, A., Hughes, S., Livy, S., McCormick, M., \& Russo, J. (2020). Ways that relentless consistency and task variation contribute to teacher and student mathematics learning. In A. Coles (Ed.), For the Learning of Mathematics Monograph 1: Proceedings of a symposium on learning in honour of Laurinda Brown (pp. 32-37). Canada: FLM Publishing Association.

Sullivan, P., \& Mornane, A. (2014). Exploring teachers' use of, and students' reactions to, challenging mathematics tasks. Mathematics Education Research Journal, 26(2), 193-213. https://doi.org/10.1007/s13394-013-0089-0

Sullivan, P., Mousley, J., \& Zevenbergen, R. (2006). Teacher actions to maximize mathematics learning opportunities in heterogeneous classrooms. International Journal of Science and Mathematics Education, 4(1), 117-143. https://doi.org/10.1007/s10763-005-9002-y

Timperley, H. S. (2005). Instructional leadership challenges: The case of using student achievement information for instructional improvement. Leadership and Policy in Schools, 4(1), 3-22. https://doi.org/10.1080/15700760590924591

Timperley, H. S., \& Phillips, G. (2003). Changing and sustaining teachers' expectations through professional development in literacy. Teaching and Teacher Education, 19(6), 627-641. https://doi.org/10.1016/s0742051x(03)00058-1

Timperley, H. S., \& Robinson, V. M. J. (2001). Achieving school improvement through challenging and changing teachers' schema. Journal of Education Change, 2, 281-300.

Tok, S., Bahtiyar, S., \& Karalökc, S. (2015). The effects of teaching mathematics creatively on academic achievement, attitudes towards mathematics, and mathematics anxiety. International Journal of Innovation in Science and Mathematics Education, 23(4), 1-24.

Valdesolo, P., Shtulman, A., \& Baron, A. S. (2017). Science is awe-some: The emotional antecedents of science learning. Emotion Review, 9(3), 215-221. https://doi.org/10.1177/1754073916673212 